OPEN ACCESS

Edited by:

Asim Biswas,

University of Guelph, Canada

Reviewed by:

Solmaz Fathololoumi,

University of Guelph, Canada

Ziqiang Ma,

Peking University, China

*Correspondence:

Ling Han

hanling@chd.edu.cn

Specialty section:

This article was submitted to

Environmental Informatics and Remote Sensing,

a section of the journal

Frontiers in Earth Science

Received: 04 July 2021 Accepted: 19 November 2021 Published: 08 December 2021

Citation:

Ma T, Han L and Liu Q (2021) Retrieving the Soil Moisture in Bare Farmland Areas Using a Modified

Dubois Model.

Front. Earth Sci. 9:735958. doi: 10.3389/feart.2021.735958

\section{Retrieving the Soil Moisture in Bare Farmland Areas Using a Modified Dubois Model}

\author{
Teng $\mathrm{Ma}^{1,2}$, Ling $\mathrm{Han}^{3,4 *}$ and Quanming $\mathrm{Liu}^{2}$ \\ ${ }^{1}$ School of Earth Science and Resources, Chang'an University, Xi'an, China, ${ }^{2}$ Water Conservancy and Civil Engineering College, \\ Inner Mongolia Agricultural University, Hohhot, China, ${ }^{3}$ Shaanxi Key Laboratory of Land Consolidation, Xi'an, China, ${ }^{4}$ College of \\ Geological Engineering and Geomatics, Chang'an University, Xi'an, China
}

Soil moisture is an important parameter for global soil moisture transport, environmental evaluation, and precision agricultural research. The accurate retrieval of soil moisture in farmland areas using Synthetic Aperture Radar (SAR) depends on the accurate description of surface and SAR parameters. In these parameters, surface roughness and incidence angle are the key factors that affect the accuracy of the soil moisture retrieval model. This article proposes a modified Dubois model to retrieve soil moisture suitable for the bare surface of farmland area. The model eliminates the incidence angle parameters and uses polarization parameters to depict the surface roughness parameters in the Dubois model. To eliminate the incidence angle, the backscattering coefficients gamma0, which eliminates the effect of the incidence angles, are used to replace the sigma0. Under rain and no rain condition, the trend of backscattering coefficients $(\mathrm{VH}$ and $\mathrm{W})$ and cross-polarization ratio $(\mathrm{VH}-\mathrm{W})$ of different soil texture with the soil moisture are compared. Then, the polarization parameter based on $\mathrm{VH}$ backscattering coefficients is used to describe surface roughness. The model is evaluated with time-series soil moisture observation data in situ of the study area. The results indicate that the modified model can retrieve soil moisture with high accuracy, and the total RMSE can reach $0.064 \mathrm{~cm}^{3} \mathrm{~cm}^{-3}$ while the Dubois model is $0.124 \mathrm{~cm}^{3} \mathrm{~cm}^{-3}$. Under rain and no rain condition, the retrieval accuracy of the modified model is $0.066 \mathrm{~cm}^{3} \mathrm{~cm}^{-3}$ and $0.063 \mathrm{~cm}^{3} \mathrm{~cm}^{-3}$. The retrieval accuracy is $0.060 \mathrm{~cm}^{3} \mathrm{~cm}^{-3}$ and $0.067 \mathrm{~cm}^{3} \mathrm{~cm}^{-3}$ under high and low incidence angles conditions, respectively. These results indicate that the modified Dubois model can retrieve soil moisture with high accuracy under different conditions.

Keywords: sentinel-1, backscattering coefficients, retrieval model, bare surface, rain

\section{INTRODUCTION}

Soil moisture is a key parameter in the Earth's water cycle (Tao et al., 2003; Ralph et al., 2013; Anagnostopoulos et al., 2017; Zhu et al., 2021). In the field of atmospheric sciences, it directly impacts the energy exchange between the hydrosphere and atmosphere. It is also a key intermediate variable that can be used to determine irrigation quota, retrieve crop growth and predict the yield of agriculturally productive fields (Zhu and Lin 2011; Rossato et al., 2017). How to accurately retrieve the soil moisture content over a large area is a meaningful scientific problem. The synthetic aperture radar (SAR) is an effective method to detect soil moisture because the microwave can avoid the disturbances from clouds, fog and rain, and it is sensitive to the dielectric constant of objects (Li et al., 2021; Petropoulos et al., 2014; Bai et al., 2015). 
The SAR-observed backscattering coefficients of soil, sigma0 $\left(\sigma^{0}\right)$, is a function of incidence angle, polarization, dielectric constant, and ground surface roughness when there is no vegetation on the ground surface. If the polarization mode and the incidence angle are fixed, the dielectric constant and surface roughness are the main factors affecting $\sigma^{0}$ (Ulaby et al., 1978; Dobson and Ulaby, 1986; Karthikeyan et al., 2017a, b). Surface roughness is generally described by the root mean square (Rms) height and correlation length, which are usually measured in situ (Ulaby et al., 1986). Since the correlation length is difficult to accurately measure, the Rms height becomes an important parameter in describing surface roughness (Dubois et al., 1995; Oh et al., 2002; Aubert et al., 2011). It is tedious to measure the Rms height in situ over large areas. Thus, many parameters, including the cross-polarization ratio (Oh, 2004; Greifeneder et al., 2018), the multi-incidence angle parameter (Srivastava et al., 2003; Shi et al., 2020) and empirical value (Srivastava et al., 2008; Rowlandson et al., 2013; McNairn et al., 2014; Benninga et al., 2019), have been used to retrieve or replace the Rms height.

The dielectric constant is another important factor that affects the backscattering coefficients, which is closely related to soil conditions such as soil texture (Leschanskiy et al., 1971; Hoekstra and Delaney, 1974; Beale et al., 2019), temperature (Dobson et al., 1985; Xu, 1985; Jin et al., 2020; Wang et al., 2020) and moisture (Stogryn, 1971; Zhang et al., 2020). Previous studies have explored many dielectric constant models, which treat soil as a mixture of soil particles, water and air. Different contents of sand, silt and clay particles will lead to differences in the dielectric constant of soil. Relative to the dielectric constant and temperature of solid soil, the influence of soil moisture on the dielectric constant of soil is more critical (Alharthi and Lange, 1987; Patel et al., 2021).

There are many models that describe the relationship between the backscattering coefficients and surface parameters. These models can be divided into three categories: theoretical models (Ulaby et al., 1990; Fung et al., 1992; Wu et al., 2001; Su and Cao, 2021), semi-empirical models (Oh et al., 2002; Oh, 2004; Yang et al., 2021; Chen et al., 2003) and empirical models (Shi et al., 1997; Baghdadi et al., 2006; Montaldo et al., 2021). Among above models, semi-empirical models are more widely used than other models. The main advantages of semi-empirical models are that they can avoid the problem of requiring too many parameters in the theoretical models and the low applicability of the empirical models. The Dubois model and the Oh model are the typical empirical models that are most widely used in practical applications. The main error sources of semi-empirical models include the errors of roughness parameters and dielectric constant model.

In previous studies about soil moisture retrieval, many alternative parameters for the Rms height have been proposed, but the parameters are easily affected by many factors, such as the precipitation, incidence direction of microwave and soil texture (Davidson et al., 2000; Benninga et al., 2019; Liao et al., 2021), so soil roughness is still an important parameter that affects the accuracy of the measured soil moisture content. Cultivating in the farmland significantly affects the surface roughness. Clarifying the backscattering characteristics and roughness description parameters in cultivated and uncultivated farmland can effectively improve the retrieval accuracy of soil moisture. Rain will also affect soil moisture. However, the response of soil moisture and backscattering coefficients to rain is related to the time and the volume of rain. Therefore, how to retrieve soil moisture under rain conditions needs further discussion. In addition, differences in soil texture are often overlooked or considered to be spatially consistent because they do not change notably with time and space. Due to differences in soil parent material, climate, and biological effects, soil texture may change considerably over small scales. Changes in the soil particle sizes will not only affect the saturated water content of soil but will also affect the soil dielectric constant.

The objectives of this research are 1) to modify the Dubois model that can retrieve soil moisture effectively without measuring surface roughness. 2) to determine the retrieval accuracy of soil moisture using modified Dubois model under different incidence angle and rain conditions. We investigate the backscattering coefficients of typical bare surface of farmland areas that have been cultivated and uncultivated. Based on this, the Dubois model is modified for soil moisture retrieval. The retrieval accuracy of the Dubois model and modified Dubois model are evaluated, and the impact of incidence angle and rain conditions on backscattering coefficients are also compared.

\section{DATASETS AND PRE-PROCESSING}

\section{Study Area}

The study area is located in the Duero Basin, northwest in Spain (Figure 1A). The geographical location of the study area is $41^{\circ} 06^{\prime} \mathrm{N}-41^{\circ} 32^{\prime} \mathrm{N}, \quad 5^{\circ} 01^{\prime} \mathrm{W}-5^{\circ} 45^{\prime} \mathrm{W} \quad$ (Figure 1B) and corresponding area is about $1,300 \mathrm{~km}^{2}$. The climate of the area belongs to the mediterranean climate, and the annual average temperature is $12^{\circ} \mathrm{C}$. The main land-use types are farmland, forest, city and water areas. The main types of crop include wheat, cereal, maize, grape and cotton. The REMEDHUS soil moisture network is established in the study area, which has 24 soil moisture observation stations (Hydra Probes, Stevens Water Monitoring System) and belongs to the International Soil Moisture Network (Dorigo et al., 2011; Dorigo et al., 2013; Campus, 2019). Probes measure $0-5 \mathrm{~cm}$ soil moisture and temperature every hour.

The geological substrate of the study area include sandstones, conglomerates, detritic limestones, and fluvial deposits of conglomerates, gravels and sands. 13 in 24 soil moisture monitoring stations were selected (Figure 1B), and other 11 fields were excluded because their observations are vegetationrelated or lack of soil moisture content during the measurement period. These 13 fields consist of two clay texture fields, six loam texture fields and five sand texture fields. A supplementary dataset which include four monitoring stations in southern France were also selected. Figures 1C-E show the bare farmland surface of clay, loam and sand texture which have been cultivated. The spacing between ridge in the fields is approximately $0.5 \mathrm{~m}$. Figure $\mathbf{1 F}$ shows the uncultivated field, the surface roughness of these part of fields is relatively small. 


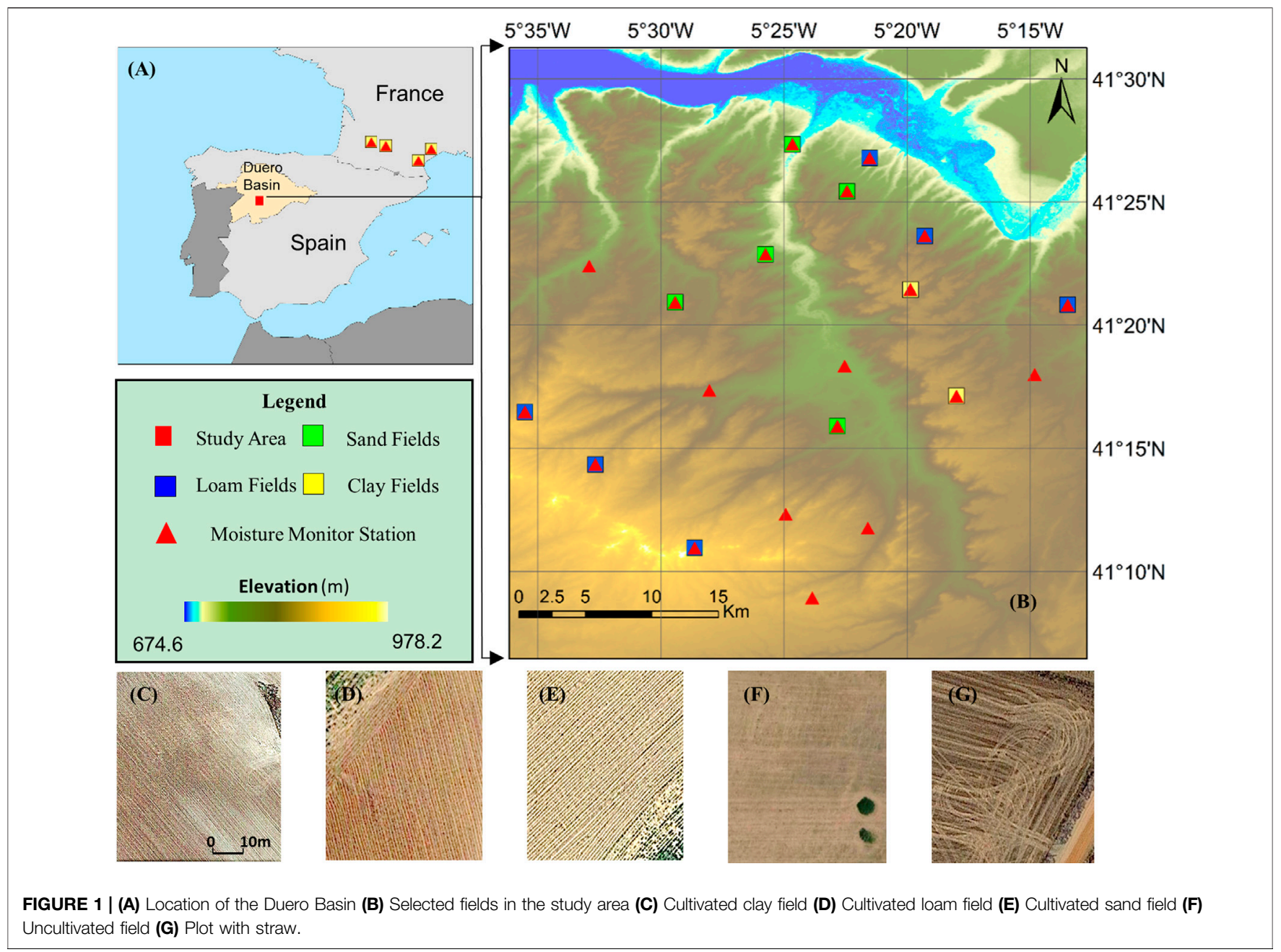

TABLE 1 | List of satellite acquired.

\begin{tabular}{|c|c|c|c|}
\hline Satellite number & Pass direction & Number of images & $\begin{array}{c}\text { Local incidence angle } \\
\text { range of study } \\
\text { area }^{a}\end{array}$ \\
\hline S1B & Descending & 33 & $31.52-47.34$ \\
\hline $\mathrm{S} 1 \mathrm{~A}$ & Ascending & 20 & $33.11-44.93$ \\
\hline S1B & Ascending & 27 & $26.66-43.14$ \\
\hline
\end{tabular}

a Local incident angle range of the study area is the incident angle range of the study fields.

Some fields contain straw, which will have a certain effect on the backscattering coefficients (Figure 1G), the data in these fields needs to be excluded.

\section{Imagery and Ground Data}

104 Sentinel-1 and 23 Sentinel-2 images, over the study area, between 2017 and 2018 were obtained from the Copernicus Open Access Hub (Copernicus, 2018). The acquisition modes of Sentinel-1 data are the interferometric (IW) mode and the level 1 ground range detected (GRD) product type, the spatial resolution of images are $20 \times 22 \mathrm{~m}$ (4.4 equivalent number of looks). The details of Sentinel-1 data are shown in Table 1. The observed Sentinel-2 data are level $1 \mathrm{C}$ or level $2 \mathrm{~A}$ products. By performing atmospheric correction on S2 level 1C data, the level $2 \mathrm{~A}$ data were obtained. The local incidence angle is calculated using SRTM $1 \mathrm{~s}$ DEM data, which has a spatial resolution of $30 \mathrm{~m}$.

The soil moisture content data were obtained from the ISMN. To reduce the impact of measurement errors, the hourly observation data in every day were averaged to obtain the daily soil moisture content. Global Satellite Mapping of Precipitation (GsMap) was obtained from Google Earth 
TABLE 2 | Soil texture of study plots.

\begin{tabular}{lcccl}
\hline Station name & \multicolumn{3}{c}{ Particle content (\%) } & Soil texture \\
\cline { 2 - 3 } & Sand & Silt & Clay & \\
\hline Carretoro & 85.47 & 9.90 & 4.63 & Sand \\
CasaPeriles & 82.43 & 7.13 & 10.45 & Loam \\
ElCoto & 85.61 & 5.87 & 8.53 & Sand \\
ElTomillar & 85.16 & 7.51 & 7.34 & Sand \\
LaCruzdeElias & 46.20 & 27.78 & 26.02 & Clay \\
LasBodegas & 77.58 & 7.78 & 14.65 & Loam \\
LasBrozas & 83.05 & 7.18 & 9.77 & Loam \\
LasTresRayas & 71.27 & 10.50 & 18.24 & Loam \\
LasVacas & 74.38 & 12.23 & 13.40 & Loam \\
LasVictorias & 90.85 & 4.02 & 5.14 & Sand \\
LlanosdelaBoveda & 47.33 & 19.72 & 32.95 & Clay \\
Paredinas & 87.27 & 9.06 & 3.67 & Sand \\
Zamarron & 79.85 & 9.74 & 10.41 & Loam \\
Lahas & 27.80 & 36.90 & 35.30 & Clay \\
LezignanCorbieres & 44.00 & 28.70 & 27.30 & Clay \\
PeyrusseGrande & 15.80 & 42.50 & 41.70 & Clay \\
Prades-le-Lez & 27.00 & 41.90 & 31.10 & Clay \\
& & & &
\end{tabular}

${ }^{a}$ Soil texture is classified according to the international soil texture classification standard.

Engine, which provides a global hourly rain rate with a $0.1 \times 0.1^{\circ}$ resolution (Gorelick et al., 2017).

Sentinel-1 images were preprocessed by the following steps: 1 ) introducing the orbit file to eliminate orbit error; 2) obtaining the backscattering coefficients based on the calibration for Sentinel-1 images; 3) A $5 \times 5$ Lee Sigma speckle filter was used to eliminate the speckle noise in the backscattering-coefficients image; 4) terrain-flattening, to eliminate radiation errors caused by spheroids and terrain fluctuations; and 5) Applying terrain correction to eliminate the geometrical error caused by spheroids and terrain fluctuations. To eliminate the variation in the backscattering coefficients caused by the different terrains and local incidence angles, a Gamma0 $\left(\gamma^{0}\right)$ images of the study area were obtained based on above steps (Small, 2011). The average $\gamma^{0}$ and local incidence angle of selected fields were calculated. Soil texture data over 17 field fields were obtained, as shown in Table 2 (Ceballos et al., 2004). Soil texture is classified according to the international soil texture classification standard. The average value such as backscattering coefficients and the local incidence angle of the fields were calculated where the monitoring stations are located. The local incidence angle was calculated using SRTM 1 s DEM data, which has a spatial resolution of $30 \mathrm{~m}$. This data can match Sentinel-1 data well because the study fields are all larger than $30 \times 30 \mathrm{~m}$.

\section{METHODS}

Procedure of developing the modified Dubois model is illustrate in Figure 2. Firstly, pre-processed Sentinel-1 and Sentinel-2 images. After the pro-processing step, the bare soil surface of study area was obtained. Secondly, the images were combined with the ground surface data, and a revised Dubois model was established based on the analysis. Finally, the modified model was verified using measurement in-situ.

\section{Dielectric Constant}

The soil dielectric constant is closely related to soil particle size, soil porosity and soil moisture. Retrieving soil moisture using microwave remote sensing depends on the characteristics of microwave, which is sensitive to the dielectric constant, so an accurate retrieval method should involve an accurate dielectric constant model. The following formula can be used to establish the relationship between soil moisture content and soil dielectric constant (Stogryn, 1971; Dobson et al., 1985):

$$
\varepsilon^{\alpha}=1+\left(\rho_{b} / \rho_{s}\right)\left(\varepsilon_{s}^{\alpha}-1\right)+m_{v}^{\beta} \varepsilon_{f w}^{\alpha}-m_{v}
$$

where $\varepsilon$ is the dielectric constant of solid soil particles and the water mixture; $\varepsilon_{s}$ is the dielectric constant of solid soils, which is equal to $4.70 ; \varepsilon_{f w}$ is the dielectric constant of free water; $\rho_{b}$ is the bulk density of soil; $\rho_{s}$ is the specific density; $m_{v}$ is the soil volumetric water content; $\alpha$ is a constant factor that equals 0.65 ; and $\beta$ is the soil texture-dependent coefficients. The real part of $\beta$ can be expressed as follows:

$$
\beta=127.48-0.519 S-0.152 \mathrm{C}
$$

where $\mathrm{S}$ is the sand content, and $\mathrm{C}$ is the clay content. When only the real part is considered, $\varepsilon_{f w}$ can be written as:

$$
\varepsilon_{f w}=\varepsilon_{w \infty}+\frac{\varepsilon_{w 0-} \varepsilon_{w \infty}}{1+\left(2 \pi \tau_{w} f\right)^{2}}
$$

where $\varepsilon_{w \infty}$ equals 4.9 , which is the high-frequency limit of $\varepsilon_{w} ; \varepsilon_{w 0}$ is the static dielectric constant of water; $\tau_{w}$ is the relaxation time of water; and $f$ is the frequency in hertz. $2 \pi \tau_{w}$ and $\varepsilon_{w 0}$ can be calculated using the following formulas:

$$
\begin{gathered}
2 \pi \tau_{w}(T, N)=2 \pi \tau_{w}(T, 0) b(N, T) \\
b(N, T)=0.1463 \times 10^{-2} N T+1.000-0.04896 N-0.02967 N^{2} \\
+5.644 \times 10^{-3} N^{3} \\
\varepsilon_{w 0}(T, N)=\varepsilon_{0}(T, 0) \alpha(N) \\
\varepsilon_{0}(T, 0)=87.24-0.4008 T+9.398 \times 10^{-4} T^{2}+1.410 \times 10^{-3} T^{3} \\
\alpha(N)=1.000-0.2551 N+5.151 \times 10^{-2} N^{2}-6.889 \times 10^{-3} N^{3} \\
N=S\left[1.707 \times 10^{-2}+1.205 \times 10^{-5} S+4.058 \times 10^{-9} S^{2}\right]
\end{gathered}
$$

where $\mathrm{T}$ is the temperature in ${ }^{\circ} \mathrm{C}$ and $\mathrm{N}$ is the normality of the solution. According to data from the Harmonized World Soil Database (HWSD, FAO/IIASA/ISRIC/ISSCAS/JRC, 2012), the conductivity of the soil in the study area is between $0.1-0.7 \mathrm{ds} / \mathrm{m}$, so the soil in the study area can be regarded as non-saline soil. So $S$ equals 0 and $\alpha(N)$ equals 1 . Since the temperature has little effect on the dielectric constant under positive temperature conditions, it can be assumed that the temperature is $10^{\circ} \mathrm{C}$.

\section{Dubois Model}

In this study, the Dubois model is modified to retrieve the soil moisture content. The Dubois model is developed based on 


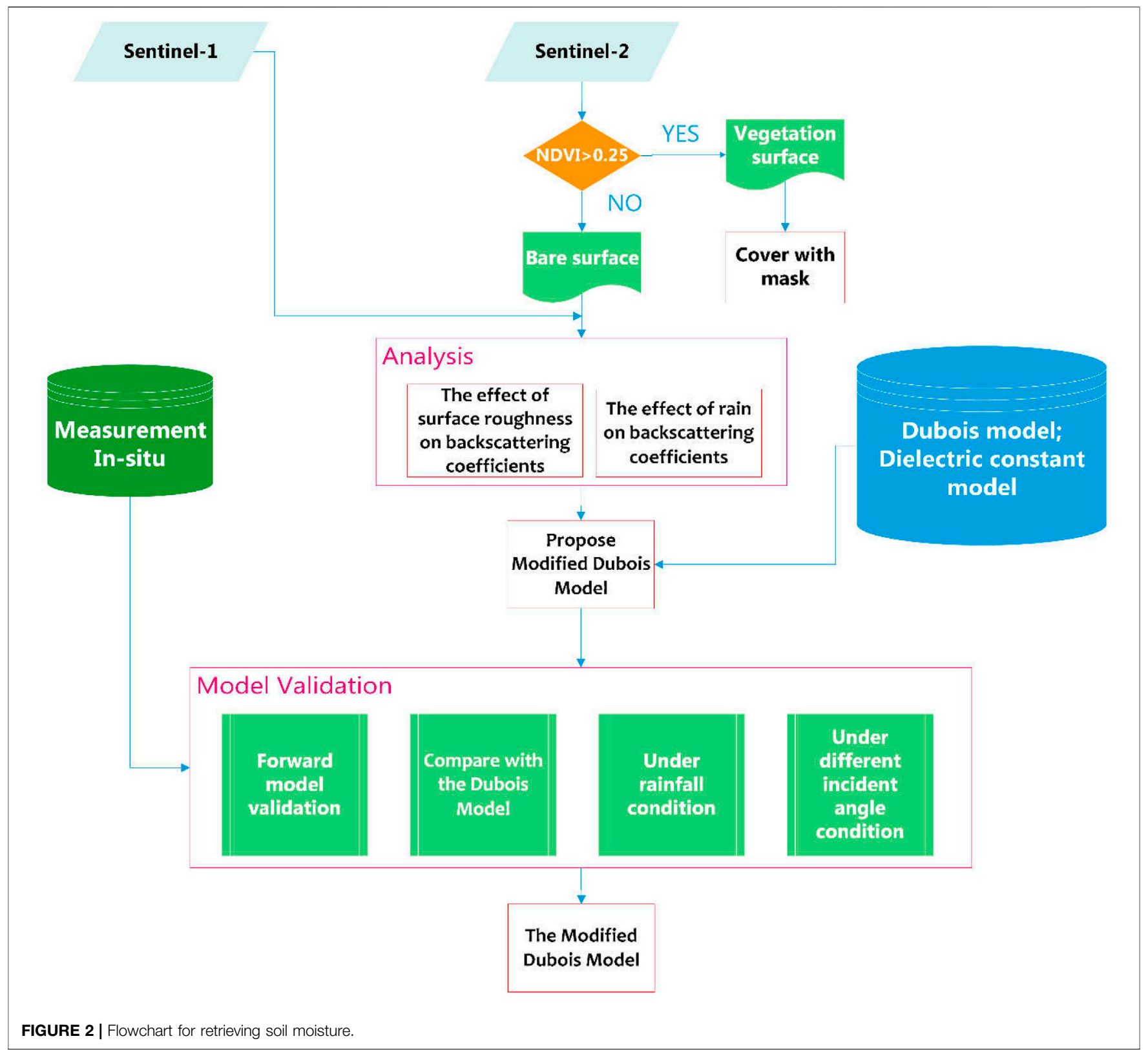

multiple ground-measured frequencies, multiple polarizations, and multiple-incidence angle scatterometer data. The model can be expressed as follows:

$$
\begin{aligned}
\sigma_{h h}^{0} & =10^{-2.75}\left(\frac{\cos ^{1.5} \theta}{\sin ^{5} \theta}\right) 10^{0.028 \varepsilon \tan \theta}(k s \sin \theta)^{1.4} \lambda^{0.7} \\
\sigma_{v v}^{0} & =10^{-2.35}\left(\frac{\cos ^{3} \theta}{\sin ^{3} \theta}\right) 10^{0.046 \varepsilon t a n} \theta(k s \sin \theta)^{1.1} \lambda^{0.7}
\end{aligned}
$$

where $\sigma_{h h}^{0}$ and $\sigma_{v v}^{0}$ are the backscattering coefficients of the Horizontal transmit and Horizontal receive $(\mathrm{HH})$ and $\mathrm{VV}$ polarizations; $\theta$ is the incidence angle; $k$ is the wavenumber; $\lambda$ is the wavelength; and $s$ is the Rms height. The radiation terrain correction method can be used to eliminate the radiation difference caused by topography. The corrected backscattering coefficients is expressed as $\gamma_{v v}^{0}$. Due to lacking of Sentinel-1 HH polarization data over the study area, only the $\mathrm{VV}$ polarization formula was selected. Thus, the final retrieval model can be expressed as:

$$
\gamma_{v v}^{0}=10^{-2.35}\left(\frac{\cos ^{3} \theta^{\prime}}{\sin ^{3} \theta^{\prime}}\right) 10^{0.046 \varepsilon \tan \theta}\left(k s \sin \theta^{\prime}\right)^{1.1} \lambda^{0.7}
$$

where $\theta^{\prime}$ is the incidence angle after radiation terrain correction.

\section{Surface Roughness}

The Rms height was used as a unique parameter to describe surface roughness. The Rms height can be expressed as a linear 


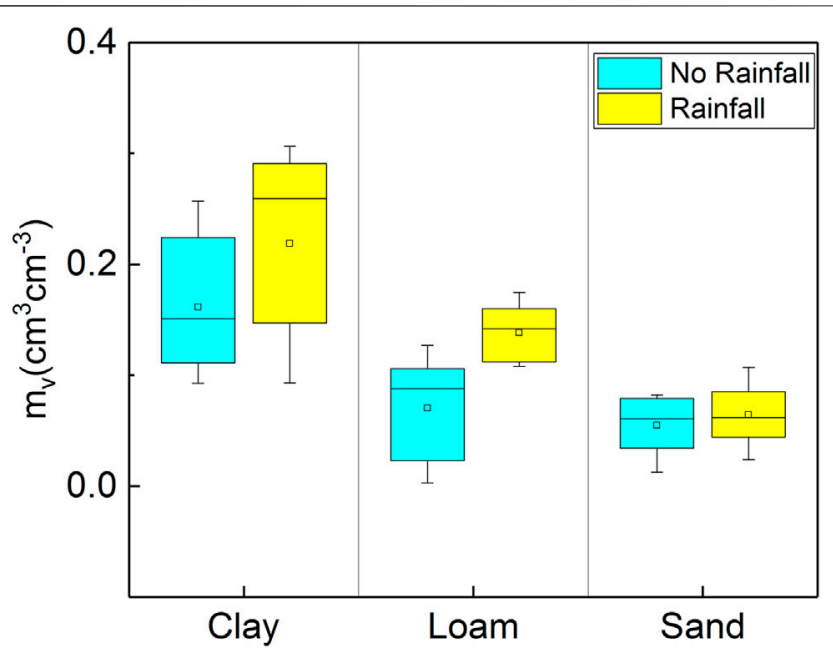

FIGURE 3 | Changes in the soil moisture content before and after rainfall.

function of the backscattering coefficients or cross-polarization ratio, which is equal to $\sigma_{V H}^{0}(d B)-\sigma_{V V}^{0}(d B)$ (Srivastava et al., 2008).

$$
\begin{gathered}
\text { Rms height }=\mathrm{A}_{1}+\mathrm{B}_{1} \times \sigma_{V H}^{0}(d B) \\
\text { Rms height }=\mathrm{A}_{2}+\mathrm{B}_{2} \times\left[\sigma_{V H}^{0}(d B)-\sigma_{V V}^{0}(d B)\right]
\end{gathered}
$$

where $\sigma_{V H}^{0}(d B)$ is the cross-polarization backscattering coefficients expressed in decibel. $A_{1}$ and $B_{1}$ are equal to 4.71 and 0.14 , respectively, $A_{2}$ and $B_{2}$ are equal to 4.27 and 0.22 , respectively. The above formula is obtained from farmland located in the states of Uttar Pradesh and Uttarakhand in India by Srivastava. To eliminate the influence of terrain, the backscattering coefficients can be expressed as $\gamma^{0}$. The following formula can be used to calculate the Rms height.

$$
\begin{gathered}
\text { Rms height }=4.71+0.14 \times \gamma_{V H}^{0}(d B) \\
\text { Rms height }=4.27+0.22 \times\left[\gamma_{V H}^{0}(d B)-\gamma_{V V}^{0}(d B)\right]
\end{gathered}
$$

where $\gamma_{V H}^{0}(d B)$ and $\gamma_{V V}^{0}(d B)$ are $\mathrm{VH}$ and $\mathrm{VV}$ polarization backscattering coefficients, respectively, which eliminate the local incidence angle effect.

\section{Data Filtering}

To avoid the effect of crops on soil moisture retrieval, it is necessary to filter the data during the research period. NDVI was used as a major indicator that judges whether the ground surface is bare. NDVI was calculated using Sentinel-2 data by the following formula:

$$
\mathrm{NDVI}=\frac{N I R-R E D}{N I R+R E D}=\frac{B_{8 A}-B_{4}}{B_{8 A}+B_{4}}
$$

where NIR is the near-infrared band reflectance; RED is the red band reflectance; and $B_{8 A}$ and $B_{4}$ are the near-infrared and RED bands of Sentinel-2. The fields were evaluated to determine whether they are bare based on the NDVI value.

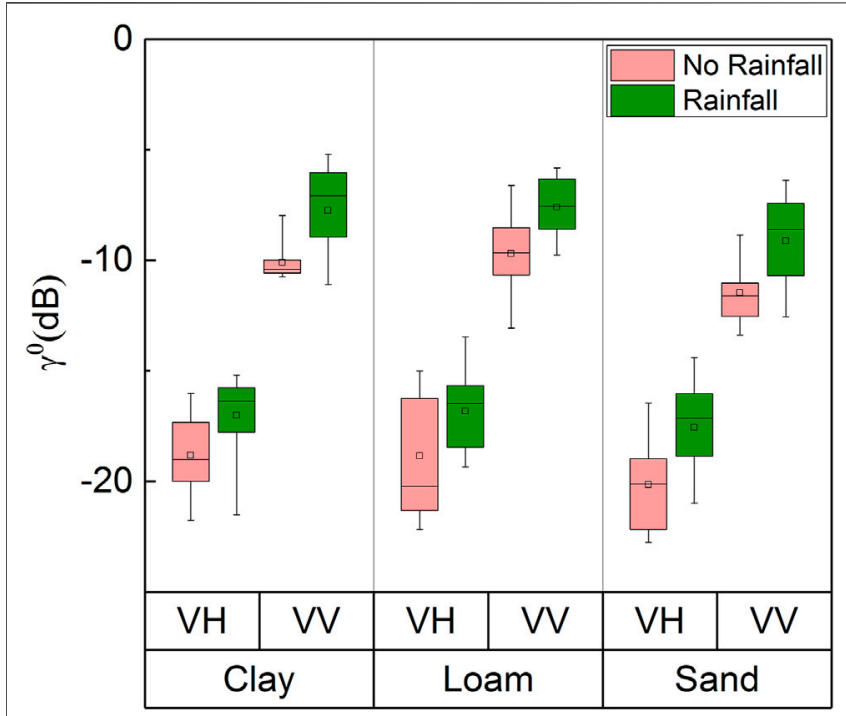

FIGURE 4 | Changes in the backscattering coefficient before and after rainfall.

NDVI values below 0.25 represent bare surface. Even so, under the condition of NDVI below 0.25, the fields contains straw and grapevines. In such a case, the backscattering value will be disturbed. To eliminate these values, the Google Earth, ESRI ArcGIS living atlas and Sentinel-2 datasets were used.

To discuss the retrieval accuracy under different climatic conditions, the data were divided into datasets with or without rain. The condition of rain refers to precipitation in $48 \mathrm{~h}$ and lasted at least $2 \mathrm{~h}$ before the observation of Sentinel-1.

\section{RESULTS}

\section{Impacts of Rain on the Surface Soil Moisture and Backscattering Coefficients}

Rain affects the soil moisture as well as the backscattering coefficients. However, the trend of change in backscattering coefficients with soil moisture is closely related to soil texture. Three typical fields (i.e., clay, loam, and sand) in cultivated and uncultivated areas are chosen to analyze. To confirm that there was no surface changes during the analysis period, Google Earth, ESRI ArcGIS living atlas and the visible light bands of Sentinel-2 data were used.

Figure 3 presents the change of the soil moisture content before and after rain. The results show that sand has a relatively lower moisture content than loam and clay regardless of rain conditions because of its large porosity and weak moisture content capacity. Owing to a lowest porosity and a strongest moisture retention capacity, Clay has highest moisture content. The soil moisture content of loam is between that of clay and sand. The soil moisture content of these three types of texture soil increased with the rain. The soil moisture content of sand changes 


$-\gamma_{V H}^{0}-\gamma_{V V}^{0} \quad-\gamma_{V H^{-}}^{0} \gamma_{V V}^{0} \quad-$ soil moisture

\section{A}

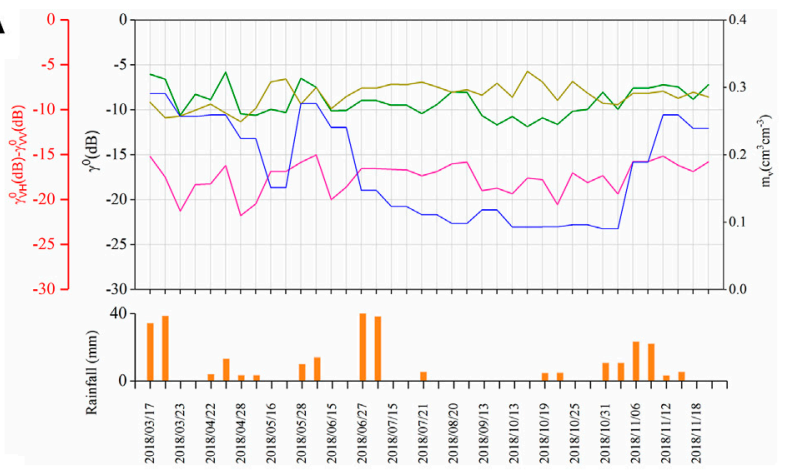

C

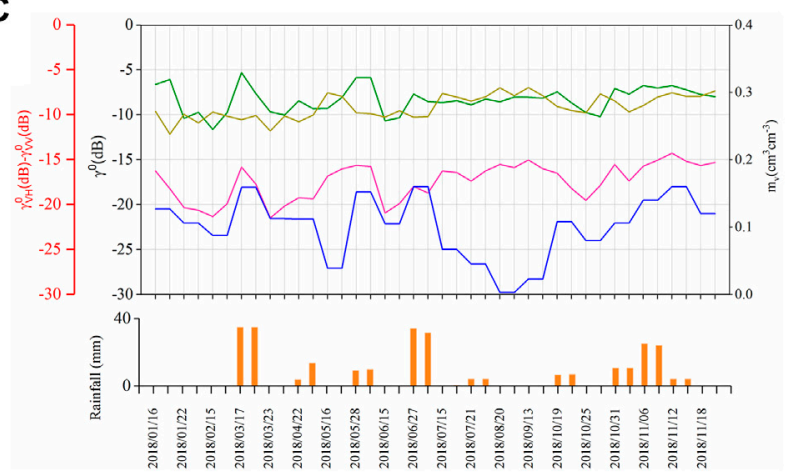

E

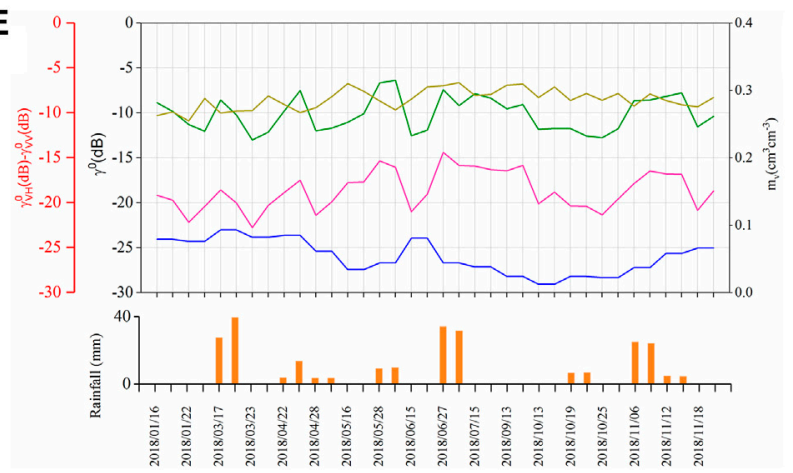

B

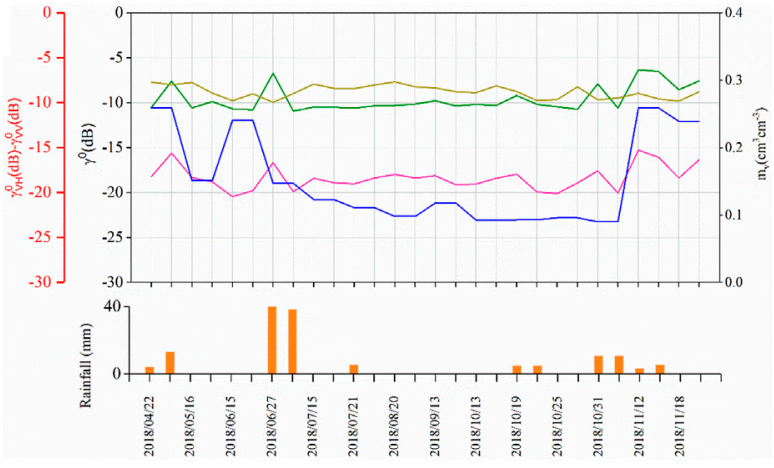

D

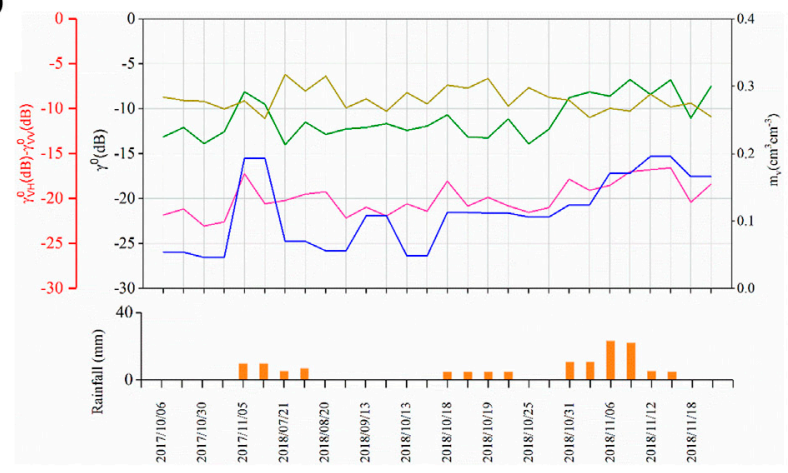

F

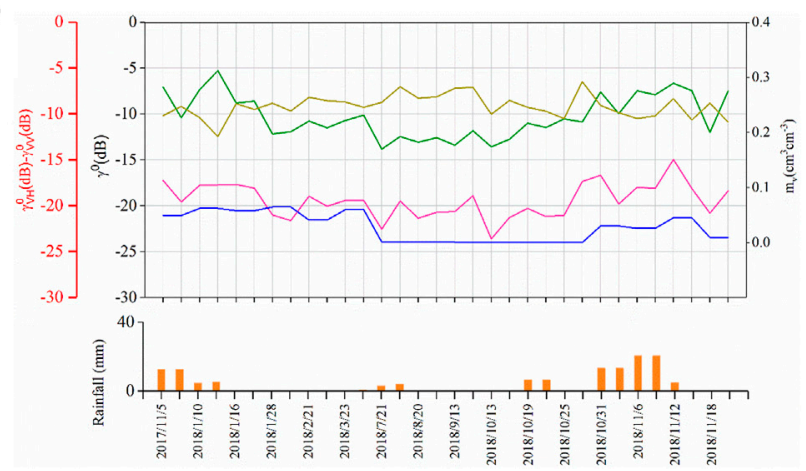

FIGURE 5 | Variation in the backscattering coefficient and polarization ratio of different soil texture plots with or without ridge structure under no rain and rain conditions. (A) Cultivated clay plot. (B) Uncultivated clay plot. (C) Cultivated loam plot. (D) Uncultivated loam plot. (E) Cultivated sand plot. (F) Uncultivated sand plot.

little after rain, which is caused by the low saturated moisture content of sand.

The backscattering coefficients of clay, loam and sand all exhibit an obvious upward trend with the appearance of rain (Figure 4). Under the condition of no rain, the backscattering coefficients of sand is slightly lower than that of clay and loam. The range of $\gamma_{V V}^{0}$ is more uniform than that of $\gamma_{V H}^{0}$, indicating that the $\mathrm{VH}$ backscattering coefficients exhibits a degree of randomness. Although the soil moisture content of the sand changes little after rain, the backscattering coefficients changes obviously. This phenomenon may be because sand has a higher dielectric constant under the same water content compared with loam and clay. VV backscattering coefficients of clay and loam increased more than $\mathrm{VH}$ after rain except for sand, indicating that VV backscattering coefficients of loam and clay are more sensitive to changes in soil moisture than $\mathrm{VH}$.

Figure 5 present the variation of soil moisture, backscattering coefficients and cross-polarization with rain. By excluding changes of the surface in the fields, each of them can be considered as no change in the surface roughness during the illustrated period. The results show that the impact of different rain degrees on soil moisture and backscattering coefficients are significantly different. The slight rain significantly increased the backscattering coefficients, but there is no significant change in 


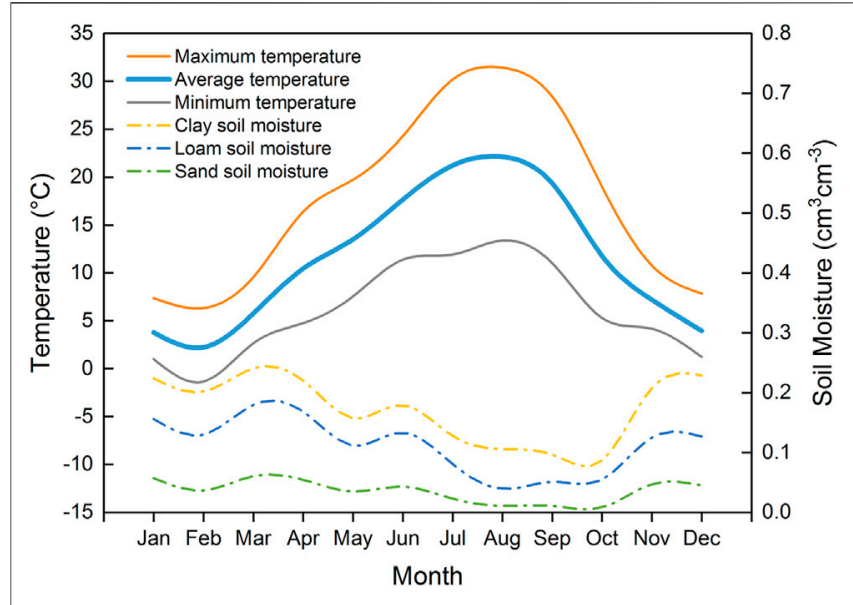

FIGURE 6 | Trends in temperature and soil moisture of study area in the 2018.

soil moisture. It can be seen that rain is an important factor affecting the backscattering coefficients and soil moisture retrieval.

\section{Impact of Surface Roughness and Other Factors on Backscattering Coefficients}

According to ground surface conditions of the fields, they can be divided into cultivated and uncultivated fields which represent rough surface (Figures 5A,C,E) and flat surface (Figures 5B,D,F). The backscattering coefficients of cultivated fields are larger than uncultivated fields, which is mainly due to greater roughness of the cultivated fields. When the soil moisture changes less, there is a degree of fluctuation in the backscattering coefficients, as shown in Figures 5A,F. Besides rain, these fluctuations are related to changes of incidence direction and penetration depth of microwave signal. The fluctuation of cultivated fields is greater than that of uncultivated fields because the status of the cultivated fields are more complex. The changes of $\gamma_{V H}^{0}$ and $\gamma_{V V}^{0}$ are very similar while $\gamma_{V H}^{0}-\gamma_{V V}^{0}$ has a quite different from $\gamma_{V V}^{0}$. In this case, when the slight rain is not taken into account and ground surface roughness is considered to be unchanged, the variation of $\gamma_{V V}^{0}$ can be seen as a result of systemic changes, such as incidence direction and penetration depth, $\gamma_{V H}^{0}$ can be considered as a valid parameter to reflect systematic fluctuations.

The backscattering coefficients of fields present a rising trend in the summer and autumn, and are more obvious in cultivated fields, but the soil moisture show downward trend. The moisture content of the surface soil in farmland areas is not only related to rain and irrigation, but also related to temperature and evaporation. The monthly temperature changes in the study area are shown in Figure 6. The results show that temperatures in the study area increased from January to August and gradually declined after September, evaporation is significantly greater in summer than in winter. In addition, the study area is located in the Mediterranean region, the winter precipitation is significantly greater than the summer precipitation, leading to significant reduction of the soil moisture in the summer and autumn. From May to October, when soil moisture decreases, the $\gamma_{V H}^{0}$ increases. The reason is microwave signal's penetration depth increases when the soil moisture declines, the amount of volume scattering increases. But within the same time period, $\gamma_{V V}^{0}$ does not significantly change. In such a case, we can still assume that $\gamma_{V H}^{0}$ is a parameter that reflects the penetration depth, and the increase in value can explain $\gamma_{V V}^{0}$ is stable and soil moisture decreases.

For the soil with different textures, the backscattering coefficients of sand is more volatile than that of clay and loam, but the moisture of soil fluctuate least, reflecting the different backscattering characteristics of different soil textures. Backscattering coefficients of sand is more susceptible to the condition of soil surfaces, and its penetration depth is more likely to produce random scattering. However, regardless of soil texture, $\gamma_{V H}^{0}$ and $\gamma_{V V}^{0}$ changing trends were consistent.

Through the above analysis, it can be seen that in addition to the rain, the $\gamma_{V H}^{0}$ is also related to systematic factors, such as the incidence direction and penetration depth. The $\gamma_{V H}^{0}$ is more closely related to these systematic states than $\gamma_{V H}^{0}-\gamma_{V V}^{0}$, so $\gamma_{V H}^{0}$ can be considered to reflect these systemic parameters more fully. Table 3 shows the correlation between backscattering coefficients and soil moisture, and the results show that the correlation between $\gamma_{V V}^{0}$ and soil moisture is higher than that of $\gamma_{V H}^{0}$ and $\gamma_{V H}^{0}-\gamma_{V V}^{0}$. Therefore, combined with the above analysis, $\gamma_{V V}^{0}$ is more suitable for describing soil moisture, $\gamma_{V H}^{0}$ is more suitable for describing soil roughness and other systematic fluctuations.

\section{The Modified Dubois Model}

The main parameters of the Dubois model include the incidence angle, surface roughness and soil moisture. According to $\gamma^{0}$, which is used as the backscattering coefficients, it can be considered that the influence of terrain and the incidence angle are eliminated. Therefore, parameter $\theta$ in the formula can be simplified and replaced with a constant. In addition, considering that the $\mathrm{VH}$ backscattering coefficients reflects the volume scattering component of the target and have a high correlation with the VV backscattering coefficients, $\gamma_{V H}^{0}$ was used to depict parameters representing the surface roughness and systematic fluctuations. The relationship between $\gamma_{V V}^{0}$ simulated by the Dubois model under different incidence angles and the actual value is shown in Figure 7. The incidence angle range of the measured data is basically distributed between $30-50^{\circ}$. Therefore, it can be considered that when the incidence angle in the model is $40^{\circ}$, the model matches the measured value best. However, there is a large angle between the trend line and the $40^{\circ}$ model line, indicating that in this situation, the accuracy of the model is low when $\gamma_{V H}^{0}$ has a large value, so the model needs to be further modified.

The roughness term coefficients and constant term in the model can be parameterized, and consider Eq. 15. The modification model can be shown as follows in $\mathrm{dB}$ form.

$$
\gamma_{v v}^{0}=-23.327+0.386 \varepsilon+27.297 \log 10\left(1.16\left(4.71+0.14 \gamma_{V H}^{0}\right)\right)
$$

The relationship between the modified model and the measured value is shown in Figure 8. 
TABLE 3 | Correlation between backscattering coefficient, cross-polarization ratio and soil moisture.

\begin{tabular}{|c|c|c|c|c|c|c|c|}
\hline & Sand (cultivated) & Sand (uncultivated) & Loam (cultivated) & Loam (uncultivated) & Clay (cultivated) & Clay (uncultivated) & Average \\
\hline$\gamma_{V H}^{0}$ & -0.27 & 0.43 & 0.72 & -0.06 & 0.11 & 0.45 & 0.23 \\
\hline$\gamma_{W}^{0}$ & -0.03 & 0.54 & 0.80 & 0.38 & 0.59 & 0.48 & 0.46 \\
\hline
\end{tabular}

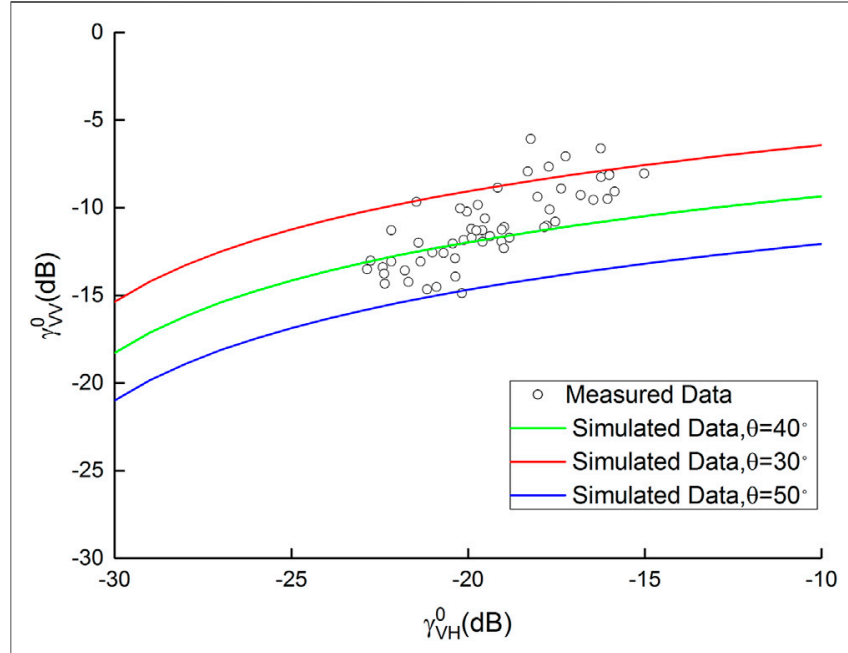

FIGURE 7 | Measured backscattering coefficients vs. modeled backscattering coefficients from the Dubois model.

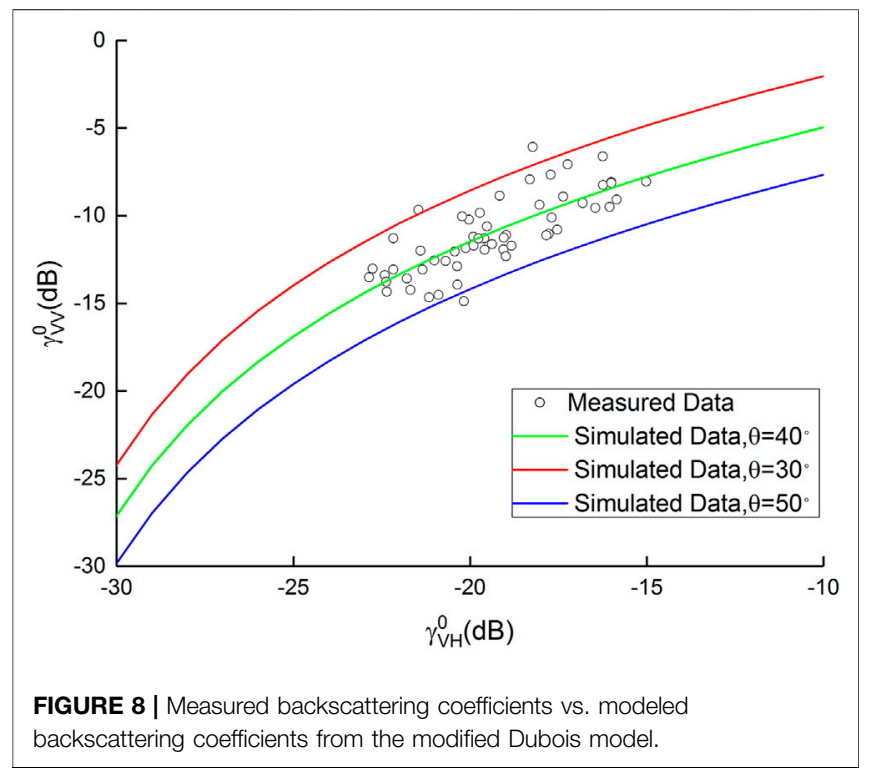

\section{Modified Dubois Model Validation Forward Model Validation}

To validate the modified Dubois model, a comparison was performed between retrieval backscattering coefficients and measured backscattering coefficients of the validation dataset (Figures 9A,B). Under no rain conditions, the correlation
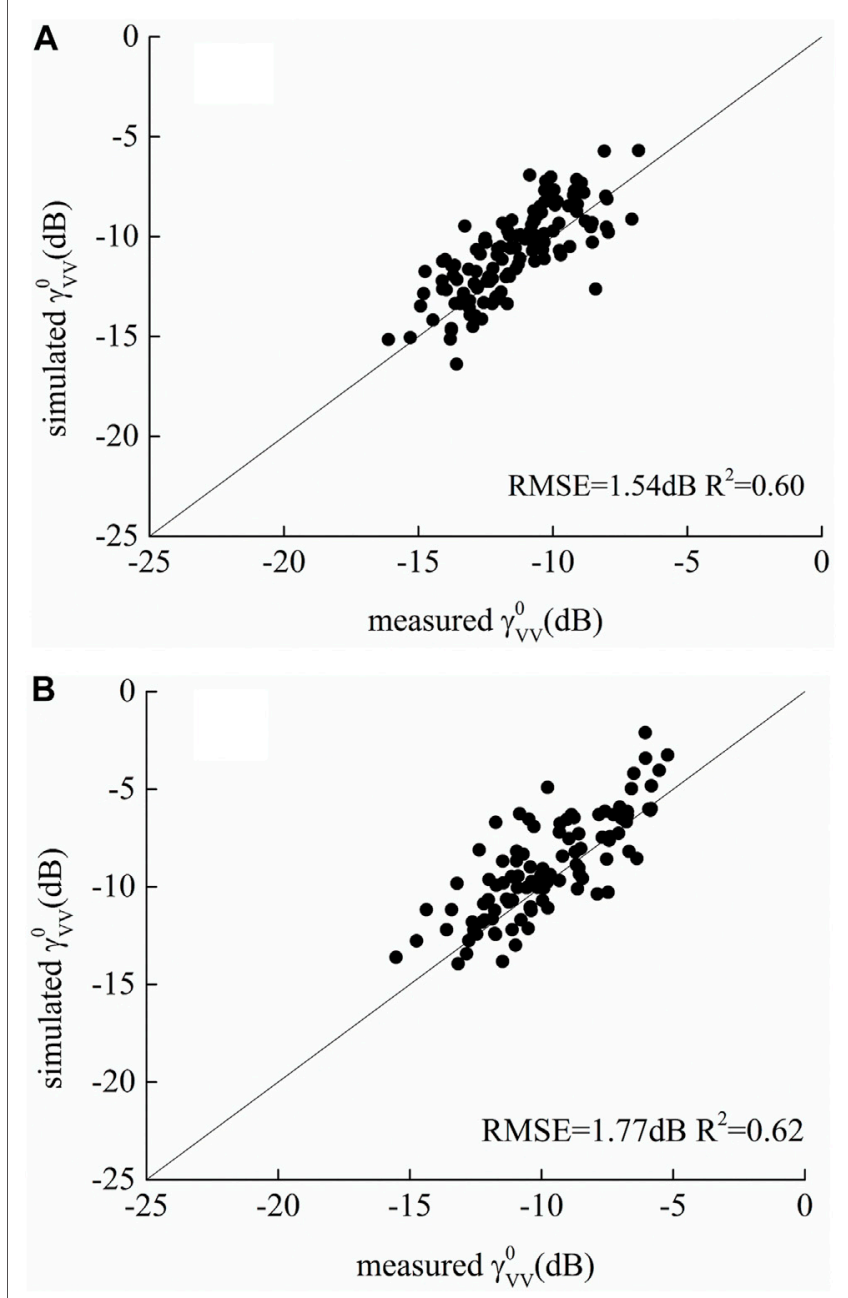

FIGURE 9 | Measured backscattering coefficient vs. modeled backscattering coefficient from the modified Dubois model. (A) No rain. (B) Rain.

coefficients is equal to 0.52 , and the RMSE is $1.56 \mathrm{~dB}$. Under rain conditions, the RMSE is equal to $1.80 \mathrm{~dB}$, and the correlation coefficients is 0.60 . Indeed, the accuracy of the model under rain conditions is close to the conditions in which there is no rain. The results show that the modified Dubois model has a better forward simulation accuracy.

The maximum difference between retrieved values using the modified model and measured values is approximately $4 \mathrm{~dB}$ under no rain conditions, and approximately $5 \mathrm{~dB}$ under rain conditions. Excluding the model error, the remaining errors 

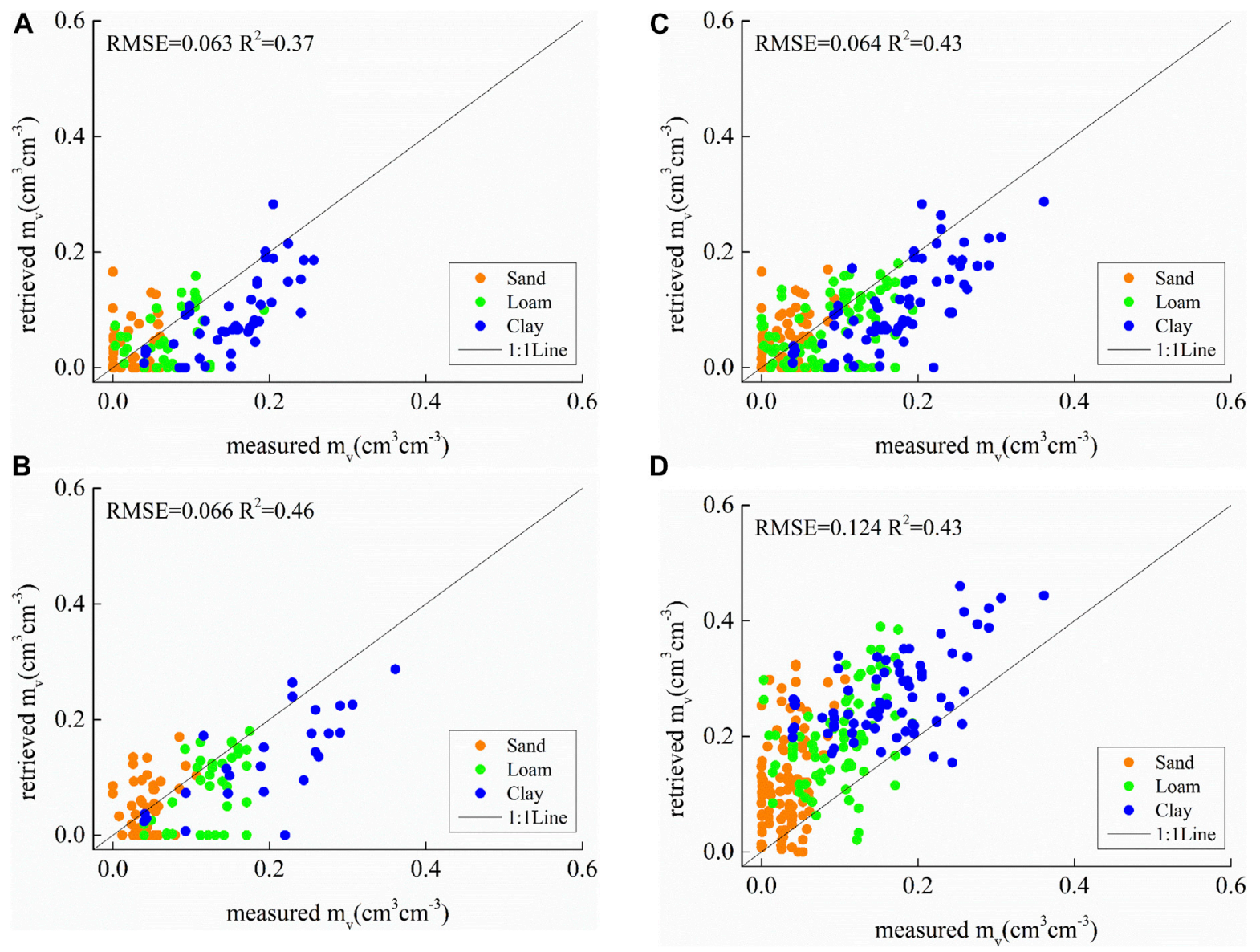

FIGURE 10 | Measured soil moisture content vs. inversion soil moisture content (A) Using modified Dubois model under no rain condition. (B) Using modified Dubois model under rain condition. (C) Overall using modified Dubois model. (D) Using Dubois model.

derive from three parts. First part is the measurement error, which includes measurement errors of $\mathrm{VV}$ and $\mathrm{VH}$ backscattering coefficients. Its magnitude is approximately $1 \mathrm{~dB}$. Second part is radiation error. Although Sentinel-1 images have been corrected by the terrain flattening procedure, there are still residual radiation errors caused by the local incidence angle. This error is affected by multiple factors, such as slope and aspect, and can reach approximately $2 \mathrm{~dB}$ in cultivated fields. Third part is the standard deviation in the determination of soil moisture content, which is approximately $0.03 \mathrm{~cm}^{3} \mathrm{~cm}^{-3}$. This error of the backscattering coefficients is related to the soil texture, its value of loam approximately equals to $2 \mathrm{~dB}$.

\section{Retrieval Accuracy of Modified Dubois Model}

The scatterplot between the measured and retrieved soil moisture are shown in Figure 10. The results show that the retrieval RMSE of the soil moisture is $0.063 \mathrm{~cm}^{3} \mathrm{~cm}^{-3}$ under no rain conditions (Figure 10A). It has a similar RMSE under rain conditions, which is equal to $0.066 \mathrm{~cm}^{3} \mathrm{~cm}^{-3}$ (Figure 10B). The overall retrieval accuracy is $0.064 \mathrm{~cm}^{3} \mathrm{~cm}^{-3}$ (Figure 10C). The retrieval RMSE of soil moisture using Dubois model is $0.124 \mathrm{~cm}^{3} \mathrm{~cm}^{-3}$
(Figure 10D). The results show that the modified Dubois model have significant improved the retrieval accuracy.

Under no rain conditions, the forecasted value of sand is not very discrete, but its compliance with the 1:1 line is poor. After the occurrence of rain, the compliance with the 1:1 line improved, and the accuracy of the model increased. At some times, the retrieval value of soil moisture was equal to 0 , which deviated greatly from the measured value because there is small amount vegetation on the ground during these periods, but its NDVI is less than the 0.25 threshold we set. The presence of a small amount of vegetation increase the $\mathrm{VH}$ polarization backscattering coefficients, which leads to a decrease in the retrieval value of soil moisture. The results of the clay fields are consistent with the 1:1 line under rain and no rain conditions, reflecting the limited effect of rain on its retrieval accuracy.

\section{Retrieval Accuracy Under Different Incidence Angle}

Although Sentinel-1 images have been corrected by calibration and terrain flattening, the difference in incidence angle may still cause a slight change of the backscattering coefficients. The retrieval RMSE of soil moisture under different incidence 
TABLE 4 | Retrieval RMSE of soil moisture content with different textures.

\begin{tabular}{llcc}
\hline Incident angle & Soil texture & Rainfall status & RMSE $\mathbf{( c m}^{\mathbf{3}} \mathbf{c m}^{\mathbf{- 3}} \mathbf{)}$ \\
\hline High & Clay & No & 0.081 \\
& Loam & & 0.064 \\
& Sand & & 0.033 \\
Overall & & 0.060 \\
Low & No & 0.079 \\
& Clay & & 0.053 \\
& Loam & & 0.054 \\
& Sand & & 0.066
\end{tabular}

angle is shown in Table 4. It can be considered as low incidence angle when the incidence angle is less than $41^{\circ}$, otherwise it is regarded as high incidence angle. Under the condition of a low incidence angle, the overall retrieval RMSE of the soil moisture is $0.066 \mathrm{~cm}^{3} \mathrm{~cm}^{-3}$, while it is equal to $0.060 \mathrm{~cm}^{3} \mathrm{~cm}^{-3}$ under high incidence angle. Therefore, it can demonstrate that the model has approximate accuracy under different incidence angles.

\section{Soil Moisture Map of the Study Area}

The soil moisture map of the study area on September 19, 2018 is shown in Figure 11. The spatial resolution of the map is $22 \mathrm{~m}$. When NDVI is greater than 0.25 , it can be considered as vegetation area, which are the green parts in the map. The bare soil area uses seven grades color to describe the moisture content. The soil moisture content of the entire study area is higher in the east than in the west. This is because the soil texture of the east region is mainly the loam and clay, and the west is the sand area. Compared with sand, clay and loam have higher soil moisture content. In addition, Due to proximity to the Duero River and its tributaries, some areas in the west also have high soil moisture content.

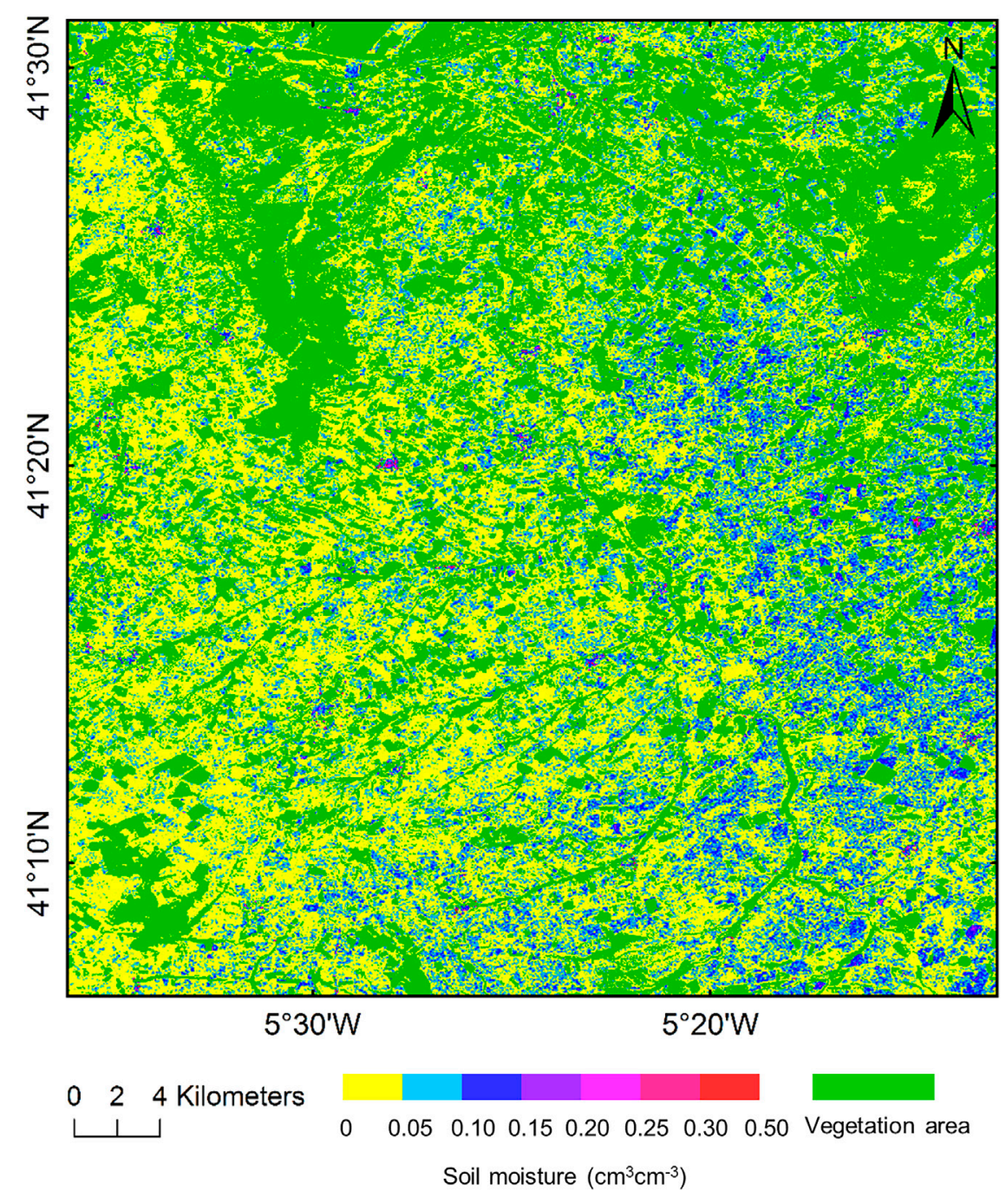

FIGURE 11 | Map of retrieval soil moisture in study area. 


\section{CONCLUSION}

To effectively improve the retrieval accuracy of soil moisture in bare farmland areas, this article investigated soil backscattering scattering characteristics of Sentinel-1 data, and a modified Dubois model was developed. The fields with moisture monitoring stations belonging to the REMEDHUS network were selected, which are located in the Duero Basin of Spain. The main soil texture of these fields are sand, loam and clay under the cultivated and uncultivated conditions. The Sentinel-1 data and soil moisture monitoring station data from 2017 to 2018 were obtained, and the NDVI dataset was calculated with the Sentinel-2 data to exclude vegetation coverage data. Based on the analysis of the timeseries backscattering coefficients of soil with different texture, the following results are obtained:

1) In addition to be affected by soil moisture and incidence angle, backscattering coefficients is also disturbed by a variety of factors, such as rain, incidence direction and penetration depth. These factors have an effect on both $\mathrm{VV}$ and $\mathrm{VH}$ polarization backscattering coefficients, and soil moisture is more significant on $\mathrm{VV}$ polarization backscattering coefficients. In particular, a small amount of rain have a great effect on the backscattering coefficients, but have a small effect on $0-5 \mathrm{~cm}$ soil moisture.

2) Cultivation have a great influence on the backscattering coefficients. The backscattering coefficients of sand have more randomness fluctuation, which reflects its susceptibility of surface interference. The backscattering coefficients of cultivated farmland areas shows a tendency of deviating from the soil moisture during the summer drought period, which is related to changes of the volume scattering component.

Based on the analysis of backscattering coefficients of typical soil texture, the modified Dubois model was developed. In the model, Rms height and other systemic fluctuations are represented by $\mathrm{VH}$ backscattering coefficients linear model. The retrieval accuracy of the modified Dubois model was evaluated:

1) No matter whether there is rain, the model has a similar retrieval accuracy. Under no rain conditions, the RMSE of the retrieved soil moisture content using the modified Dubois model is $0.063 \mathrm{~cm}^{3} \mathrm{~cm}^{-3}$, and the RMSE is $0.066 \mathrm{~cm}^{3} \mathrm{~cm}^{-3}$ under rain conditions. Without considering the soil texture and climatic conditions, the overall retrieval RMSE of the model is $0.064 \mathrm{~cm}^{3} \mathrm{~cm}^{-3}$, and $R^{2}$ is equal to 0.43 . Compared to the original Dubois model, the accuracy of the modified model is significantly improved.

\section{REFERENCES}

Alharthi, A., and Lange, J. (1987). Soil Water Saturation: Dielectric Determination. Water Resour. Res. 23, 591-595. doi:10.1029/wr023i004p00591

Anagnostopoulos, V., Petropoulos, G. P., Ireland, G., and Carlson, T. N. (2017). A Modernized Version of a 1D Soil Vegetation Atmosphere
2) The incidence angle has a small effect on the modified Dubois model, with an overall retrieval error of $0.060 \mathrm{~cm}^{3} \mathrm{~cm}^{-3}$ under high incidence angle and $0.066 \mathrm{~cm}^{3} \mathrm{~cm}^{-3}$ under low incidence angle under no rain conditions.

This study reveals the influence of surface roughness and climatic condition on the backscattering coefficients. The modified Dubois model can obtain high accuracy soil moisture retrieval value under a variety of soil texture conditions. Further investigations are necessary to analyze the trend of the backscattering coefficients of bare farmland areas under freezing and thawing conditions. In addition, the influence of different texture soil and farming states on the backscattering coefficients under the condition of vegetation coverage need to be discussed and a soil moisture retrieval model under frozen and vegetation-covered farmland needs to be established.

\section{DATA AVAILABILITY STATEMENT}

Publicly available datasets were analyzed in this study. This data can be found here: https://scihub.copernicus.eu/dhus/\#/home, https:// ismn.geo.tuwien.ac.at/en/ and https://earthengine.google.com/.

\section{AUTHOR CONTRIBUTIONS}

TM and LH carried out methodology and analyzed the data. QL designed the research. TM implemented the research and wrote the manuscript. All authors edited the manuscript.

\section{FUNDING}

This research was funded by Fundamental Research Funds for the Central Universities, CHD, Grant number (300102270501), Science and technology Research project for university of Inner Mongolia Autonomous Region (NJZY21498), National Natural Science Foundation of China (52069020), Mongolia Agricultural University "Double First Class" Discipline Innovation Team Building Talent Cultivation Project, Grand number (NDSC2018-10).

\section{ACKNOWLEDGMENTS}

The authors would like to express their gratitude to the reviewers for their valuable comments and suggestions for improving this manuscript.

Transfer Model for Improving its Future Use in Land Surface Interactions Studies. Environ. Model. Softw. 90, 147-156. doi:10.1016/ j.envsoft.2017.01.004

Aubert, M., Baghdadi, N., Zribi, M., Douaoui, A., Loumagne, C., Baup, F., et al. (2011). Analysis of TerraSAR-X Data Sensitivity to Bare Soil Moisture, Roughness, Composition and Soil Crust. Remote Sensing Environ. 115, 1801-1810. doi:10.1016/j.rse.2011.02.021 
Baghdadi, N., Holah, N., and Zribi, M. (2006). Soil Moisture Estimation Using Multi-incidence and Multi-polarization ASAR Data. Int. J. Remote Sensing 27, 1907-1920. doi:10.1080/01431160500239032

Bai, X., He, B., and Li, X. (2015). Optimum Surface Roughness to Parameterize Advanced Integral Equation Model for Soil Moisture Retrieval in Prairie Area Using Radarsat-2 Data. IEEE Trans. Geosci. Remote Sensing 54, 2437-2449. doi:10.1109/tgrs.2015.2501372

Beale, J., Snapir, B., Waine, T., Evans, J., and Corstanje, R. (2019). The Significance of Soil Properties to the Estimation of Soil Moisture from C-Band Synthetic Aperture Radar. Hydrol. Earth Syst. Sci. Discuss., 1-32. doi:10.5194/hess2019-294

Benninga, H.-J., van der Velde, R., and Su, Z. (2019). Impacts of Radiometric Uncertainty and Weather-Related Surface Conditions on Soil Moisture Retrievals with Sentinel-1. Remote Sensing 11, 2025. doi:10.3390/rs11172025

Campus (2019). Grupo de Investigación en Recursos Hídricos de la Universidad de Salamanca (HIDRUS). Available at: http://campus.usal.es/ hidrus/ (accessed on November 4, 2019).

Chen, K. S., Tzong-Dar Wu, T. D., Leung Tsang, L., Qin Li, Q., Jiancheng Shi, J. C., and Fung, A. K. (2003). Emission of Rough Surfaces Calculated by the Integral Equation Method with Comparison to Three-Dimensional Moment Method Simulations. IEEE Trans. Geosci. Remote Sensing 41, 90-101. doi:10.1109/ tgrs.2002.807587

Copernicus (2018). Copernicus Open Access Hub. Available at: https://scihub. copernicus.eu/ (accessed on October 29, 2018).

Davidson, M. W. J., Thuy Le Toan, T., Mattia, F., Satalino, G., Manninen, T., and Borgeaud, M. (2000). On the Characterization of Agricultural Soil Roughness for Radar Remote Sensing Studies. IEEE Trans. Geosci. Remote Sensing 38, 630-640. doi:10.1109/36.841993

Dobson, M., and Ulaby, F. (1986). Active Microwave Soil Moisture Research. IEEE Trans. Geosci. Remote Sensing GE-24, 23-36. doi:10.1109/ tgrs.1986.289585

Dobson, M., Ulaby, F., Hallikainen, M., and El-rayes, M. (1985). Microwave Dielectric Behavior of Wet Soil-Part II: Dielectric Mixing Models. IEEE Trans. Geosci. Remote Sensing GE-23, 35-46. doi:10.1109/tgrs.1985.289498

Dorigo, W. A., Wagner, W., Hohensinn, R., Hahn, S., Paulik, C., Xaver, A., et al. (2011). The International Soil Moisture Network: a Data Hosting Facility for Global In Situ Soil Moisture Measurements. Hydrol. Earth Syst. Sci. 15, 1675-1698. doi:10.5194/hess-15-1675-2011

Dorigo, W. A., Xaver, A., Vreugdenhil, M., Gruber, A., Hegyiová, A., SanchisDufau, A. D., et al. (2013). Global Automated Quality Control of In Situ Soil Moisture Data from the International Soil Moisture Network. Vadose Zone J. 12, 1-21. doi:10.2136/vzj2012.0097

Dubois, P. C., van Zyl, J., and Engman, T. (1995). Measuring Soil Moisture with Imaging Radars. IEEE Trans. Geosci. Remote Sensing 33, 915-926. doi:10.1109/ tgrs.1995.47719410.1109/36.406677

FAO/IIASA/ISRIC/ISSCAS/JRC (2012). Harmonized World Soil Database (Version 1.2). Rome, Laxenburg, Austria: FAOItaly and IIASA.

Fung, A. K., Li, Z., and Chen, K. S. (1992). Backscattering from a Randomly Rough Dielectric Surface. IEEE Trans. Geosci. Remote Sensing 30, 356-369. doi:10.1109/36.134085

Gorelick, N., Hancher, M., Dixon, M., Ilyushchenko, S., Thau, D., and Moore, R. (2017). Google Earth Engine: Planetary-Scale Geospatial Analysis for Everyone. Remote Sensing Environ. 202, 18-27. doi:10.1016/j.rse.2017.06.031

Greifeneder, F., Notarnicola, C., Hahn, S., Vreugdenhil, M., Reimer, C., Santi, E., et al. (2018). The Added Value of the VH/VV Polarization-Ratio for Global Soil Moisture Estimations from Scatterometer Data. IEEE J. Sel. Top. Appl. Earth Observations Remote Sensing 11, 3668-3679. doi:10.1109/ JSTARS.2018.2865185

Hoekstra, P., and Delaney, A. (1974). Dielectric Properties of Soils at UHF and Microwave Frequencies. J. Geophys. Res. 79, 1699-1708. doi:10.1029/ jb079i011p01699

Jin, X., Yang, W., Gao, X., and Li, Z. (2020). Analysis and Modeling of the Complex Dielectric Constant of Bound Water with Application in Soil Microwave Remote Sensing. Remote Sensing 12, 3544. doi:10.3390/rs12213544

Karthikeyan, L., Pan, M., Wanders, N., Kumar, D. N., and Wood, E. F. (2017a). Four Decades of Microwave Satellite Soil Moisture Observations: Part 1. A Review of Retrieval Algorithms. Adv. Water Resour. 109, 106-120. doi:10.1016/ j.advwatres.2017.09.006
Karthikeyan, L., Pan, M., Wanders, N., Kumar, D. N., and Wood, E. F. (2017b). Four Decades of Microwave Satellite Soil Moisture Observations: Part 2. Product Validation and Inter-satellite Comparisons. Adv. Water Resour. 109, 236-252. doi:10.1016/j.advwatres.2017.09.010

Leshchanskii, Y. I., Lebedeva, G. N., and Shumilin, V. D. (1971). The Electrical Parameters of sandy and Loamy Soils in the Range of Centimeter, Decimeter, and Meter Wavelengths. Radiophys Quan. Electron 14, 445-451. doi:10.1007/ bf01030730

Li, Z.-L., Leng, P., Zhou, C., Chen, K.-S., Zhou, F.-C., and Shang, G.-F. (2021). Soil Moisture Retrieval from Remote Sensing Measurements: Current Knowledge and Directions for the Future. Earth-Science Rev. 218, 103673. doi:10.1016/ j.earscirev.2021.103673

Liao, T.-H., Kim, S.-B., Handwerger, A., Fielding, E., Cosh, M., and Schulz, W. (2021). High-Resolution Soil-Moisture Maps over Landslide Regions in Northern California Grassland Derived from SAR Backscattering Coefficients. IEEE J. Sel. Top. Appl. Earth Observations Remote Sensing 14, 4547-4560. doi:10.1109/JSTARS.2021.3069010

McNairn, H., Jackson, T. J., Wiseman, G., Belair, S., Berg, A., Bullock, P., et al. (2014). The Soil Moisture Active Passive Validation experiment 2012 (SMAPVEX12): Prelaunch Calibration and Validation of the SMAP Soil Moisture Algorithms. IEEE Trans. Geosci. Remote Sensing 53, 2784-2801. doi:10.1109/tgrs.2014.2364913

Montaldo, N., Fois, L., and Corona, R. (2021). Soil Moisture Estimates in a Grass Field Using Sentinel-1 Radar Data and an Assimilation Approach. Remote Sensing 13, 3293. doi:10.3390/rs13163293

Oh, Y., Sarabandi, K., and Ulaby, F. T. (2002). Semi-Empirical Model of the Ensemble-Averaged Differential Mueller Matrix for Microwave Backscattering from Bare Soil Surfaces. IEEE Trans. Geosci. Remote Sensing 40, 1348-1355. doi:10.1109/tgrs.2002.800232

Oh, Y. (2004). Quantitative Retrieval of Soil Moisture Content and Surface Roughness from Multipolarized Radar Observations of Bare Soil Surfaces. IEEE Trans. Geosci. Remote Sensing 42, 596-601. doi:10.1109/tgrs.2003.821065

Patel, V. N., Chaudhary, P. D., Rana, V. A., and Gadani, D. H. (2021). Estimation of Dielectric Properties of clay Loam and Silty Soil with Different Salinity Levels over Low Frequency Range. Curr. Sci. 120, 414-422. doi:10.18520/cs/v120/i2/ 414-422

Petropoulos, G. P., Ireland, G., Srivastava, P. K., and Ioannou-Katidis, P. (2014). An Appraisal of the Accuracy of Operational Soil Moisture Estimates from SMOS MIRAS Using Validated In Situ Observations Acquired in a Mediterranean Environment. Int. J. Remote Sensing 35, 5239-5250. doi:10.1080/ 2150704x.2014.933277

Ralph, F. M., Coleman, T., Neiman, P. J., Zamora, R. J., and Dettinger, M. D. (2013). Observed Impacts of Duration and Seasonality of Atmospheric-River Landfalls on Soil Moisture and Runoff in Coastal Northern California. J. Hydrometeorol. 14, 443-459. doi:10.1175/jhm-d-12-076.1

Rossato, L., Alvalá, R. C. d. S., Marengo, J. A., Zeri, M., Cunha, A. P. M. d. A., Pires, L. B. M., et al. (2017). Impact of Soil Moisture on Crop Yields over Brazilian Semiarid. Front. Environ. Sci. 5, 73. doi:10.3389/fenvs.2017.00073

Rowlandson, T. L., Berg, A. A., Bullock, P. R., Ojo, E. R., McNairn, H., Wiseman, G., et al. (2013). Evaluation of Several Calibration Procedures for a Portable Soil Moisture Sensor. J. Hydrol. 498, 335-344. doi:10.1016/ j.jhydrol.2013.05.021

Jiancheng Shi, J., Wang, J., Hsu, A. Y., O’Neill, P. E., and Engman, E. T. (1997). Estimation of Bare Surface Soil Moisture and Surface Roughness Parameter Using L-Band SAR Image Data. IEEE Trans. Geosci. Remote Sensing 35, 1254-1266. doi:10.1109/36.628792

Shi, H., Lopez-Sanchez, J. M., Yang, J., Li, P., Zhao, L., and Zhao, J. (2020). Contribution of Polarimetry and Multi-Incidence to Soil Moisture Estimation over Agricultural Fields Based on Time Series of L-Band SAR Data. IEEE J. Sel. Top. Appl. Earth Observations Remote Sensing 14, 300-313. doi:10.1109/ JSTARS.2020.3036732

Small, D. (2011). Flattening Gamma: Radiometric Terrain Correction for SAR Imagery. IEEE Trans. Geosci. Remote Sensing 49, 3081-3093. doi:10.1109/ tgrs.2011.2120616

Srivastava, H. S., Patel, P., Manchanda, M. L., and Adiga, S. (2003). Use of Multiincidence Angle RADARSAT-1 SAR Data to Incorporate the Effect of Surface Roughness in Soil Moisture Estimation. IEEE Trans. Geosci. Remote Sensing 41, 1638-1640. doi:10.1109/tgrs.2003.813356 
Srivastava, H. S., Patel, P., Navalgund, R. R., and Sharma, Y. (2008). Retrieval of Surface Roughness Using Multi-Polarized Envisat-1 ASAR Data. Geocarto Int. 23, 67-77. doi:10.1080/10106040701538157

Stogryn, A. (1971). Equations for Calculating the Dielectric Constant of Saline Water (Correspondence). IEEE Trans. Microwave Theor. Techn. 19, 733-736. doi:10.1109/tmtt.1971.1127617

$\mathrm{Su}, \mathrm{C}$, and Cao, Y. (2021). Research on Inversion of Soil Moisture in Karst Area Based on Full-Polarization SAR Data. IEEE Access 9, 117512-117519. doi:10.1109/ACCESS.2021.3106768

Tao, F., Yokozawa, M., Hayashi, Y., and Lin, E. (2003). Future Climate Change, the Agricultural Water Cycle, and Agricultural Production in China. Agric. Ecosyst. Environ. 95, 203-215. doi:10.1016/s0167-8809(02)00093-2

Ulaby, F., Batlivala, P., and Dobson, M. (1978). Microwave Backscatter Dependence on Surface Roughness, Soil Moisture, and Soil Texture: Part I-Bare Soil. IEEE Trans. Geosci. Electron. 16, 286-295. doi:10.1109/tge.1978.294586

Ulaby, F. T., Moore, R. K., and Fung, A. (1986). Microwave Remote Sensing: Active and Passive 2-Radar Remote Sensing and Surface Scattering and Emission Theory. Massachusetts: Artech House press.

Ulaby, F. T., Sarabandi, K., Mcdonald, K., Whitt, M., and Dobson, M. C. (1990). Michigan Microwave Canopy Scattering Model. Int. J. Remote Sensing 11, 1223-1253. doi:10.1109/igarss.1988.57050610.1080/01431169008955090

Wang, S., Sun, Q., Wang, N., and Yang, L. (2020). Variation in the Dielectric Constant of limestone with Temperature. Bull. Eng. Geol. Environ. 79, 1349-1355. doi:10.1007/s10064-019-01647-3

Wu, T. D., Chen, K. S., Jiancheng Shi, J., and Fung, A. K. (2001). A Transition Model for the Reflection Coefficient in Surface Scattering. IEEE Trans. Geosci. Remote Sensing 39, 2040-2050. doi:10.1109/igarss.1998.70221810.1109/36.951094

$\mathrm{Xu}, \mathrm{X}$. Z. (1985). Soil-Water Potential and Unfrozen Water Content and Temperature. J. Glaciol. Geocryol. 7, 1-14.
Yang, M., Wang, H., Tong, C., Zhu, L., Deng, X., Deng, J., et al. (2021). Soil Moisture Retrievals Using Multi-Temporal Sentinel-1 Data over Nagqu Region of Tibetan Plateau. Remote Sensing 13, 1913. doi:10.3390/rs13101913

Zhang, L., Meng, Q., Hu, D., Zhang, Y., Yao, S., and Chen, X. (2020). Comparison of Different Soil Dielectric Models for Microwave Soil Moisture Retrievals. Int. J. Remote Sensing 41, 3054-3069. doi:10.1080/01431161.2019.1698077

Zhu, Q., and Lin, H. (2011). Influences of Soil, Terrain, and Crop Growth on Soil Moisture Variation from Transect to Farm Scales. Geoderma 163, 45-54. doi:10.1016/j.geoderma.2011.03.015

Zhu, Y., Liu, Y., Wang, W., Singh, V. P., and Ren, L. (2021). A Global Perspective on the Probability of Propagation of Drought: From Meteorological to Soil Moisture. J. Hydrol. 603, 126907. doi:10.1016/j.jhydrol.2021.126907

Conflict of Interest: The authors declare that the research was conducted in the absence of any commercial or financial relationships that could be construed as a potential conflict of interest.

Publisher's Note: All claims expressed in this article are solely those of the authors and do not necessarily represent those of their affiliated organizations, or those of the publisher, the editors and the reviewers. Any product that may be evaluated in this article, or claim that may be made by its manufacturer, is not guaranteed or endorsed by the publisher.

Copyright (c) $2021 \mathrm{Ma}$, Han and Liu. This is an open-access article distributed under the terms of the Creative Commons Attribution License (CC BY). The use, distribution or reproduction in other forums is permitted, provided the original author(s) and the copyright owner(s) are credited and that the original publication in this journal is cited, in accordance with accepted academic practice. No use, distribution or reproduction is permitted which does not comply with these terms. 